\title{
Novel Biosensor for the Rapid Measurement of Estrogen Based on a Ligand-Receptor Interaction
}

\author{
Masaharu Murata, Masamichi Nakayama, Hiroshi IrIE, Keiko Yakabe, Kaori Fukuma, \\ Yoshiki Katayama, and Mizuo MaEda \\ Department of Materials Physics and Chemistry, Graduate School of Engineering, Kyushu University, \\ Fukuoka 812-8581, Japan
}

\begin{abstract}
A bioaffinity sensor was developed aiming at the detection of estrogen. This biosensor system is based on the specific binding of estrogen to its receptor immobilized on a gold disk electrode. The recombinant DNA encoding human estrogen receptor ligand-binding domain was expressed in bacteria using the histidine-tag fusion system. The expression of the fusion protein was under control of a bacteriophage $\mathrm{T} 7$ promoter, and the protein was purified under native conditions by affinity chromatography, which is based on a specific interaction between a histidine-tag, located in the Nterminus of the protein, and the Ni(II) chelate adsorbent. The protein was immobilized on an Au-electrode with Ni(II)mediated chemisorption using a histidine tag and thiol-modified iminodiacetic acid. Cyclic voltammetric measurements showed that the reversible electrochemical reaction of a ferrocyanide/ferricyanide redox couple was suppressed by the presence of estrogen in a concentration-dependent manner. It seems reasonable to suppose that the electrostatic property of the protein layer on the electrode surface was altered by complexation with estrogen. These data suggest that this biosensor is applicable to the evaluation binding activities of the chemicals toward the human estrogen receptor.
\end{abstract}

(Received September 27, 2000; Accepted November 22, 2000)

\section{Introduction}

The endocrine-disruptor hypothesis asserts that exogenous substances with estrogenic or other hormonally active properties may adversely affect wildlife and human health. While it is clear that a spectrum of in vivo screens may be required to characterize a compound as an endocrine disruptor that can cause adverse effects in exposed organisms, in vitro assays are required to define the molecular mechanisms responsible for these effects. ${ }^{1,2}$

Steroid hormones, including estrogen, elicit numerous effects in mammalian cells and tissues with binding to specific intercellular receptors that function as ligand-dependent transcription factors. ${ }^{3}$ Many endocrine disruptors are also believed to bind to the estrogen receptor (ER) as an agonist or an antagonist. Thus, the binding ability of the chemicals toward ER would be a crucial factor for screening or testing of their potential environmental toxicity. Competitive ligand binding assays, in which the test compound displaces a receptor-bound probe molecule, have been used for characterizing chemicals as an endocrine disruptor. Although these assays are suitable for large-scale screening of estrogenic substances, they still have a number of disadvantages, including the use of crude receptor preparations from cells or tissue, testing under physiological conditions, and the use of radioisotopes. Furthermore, these assays also require separation steps of an unbound tracer and are time-consuming. ${ }^{1}$ Here, we propose a novel assay system based on specific receptor binding to detect estrogenic compounds using sensor technology.

Biosensors have attracted considerable attention in meeting the analytical measurement needs of biotechnology and biomedicine because of their extraordinary sensitivities and specificities. ${ }^{4}$ The basic feature of a bioelectronic device is the immobilization of a biomaterial, such as an antibody or an enzyme, onto a conductive or semi-conductive support, and the electronic transduction of the biological functions associated with the biological matrices. ${ }^{5}$ However, it may be difficult to adopt this technique for constructing an estrogen biosensor using a nuclear receptor-modified electrode, because affinity reactions between the nuclear receptors and their ligands are not directly linked to redox processes. On the other hand, we previously reported new types of biosensor for detecting DNA, ${ }^{6}$ DNA binding substrates, ${ }^{7}$ anti-DNA antibodies, ${ }^{8}$ or cyclicAMP, ${ }^{9}$ using the concept of an "ion-channel mechanism", which was proposed by Sugawara et al. ${ }^{10}$ In the present study, we constructed a new type of electrochemical sensing system using this mechanism. The bioaffinity sensor was applied for the detection of $17 \beta$-estradiol, which is a typical female sex steroid.

\section{Experimental}

DNA construction and expression of the histidine-tagged ligand-binding domain of the human ER

Restriction enzymes were obtained from New England Biolabs (USA). T4 DNA ligase was obtained from Takara. The plasmid pHEGO-Hyg encoding full-length human ER $\alpha$ was kindly provided by T. C. Spelsberg and S. A. Harris. Laboratory chemicals were of reagent grade.

pEThER-LBD, which expresses a histidine-tag fused with the ligand-binding domain (residues 302-553) of human ER $\alpha$, was cloned by PCR. The primers for hER containing NdeI and BamHI sites are $5^{\prime}$ GGAATTCCATATGTCTAAGAAGAACAGCCTGGC-3' and 


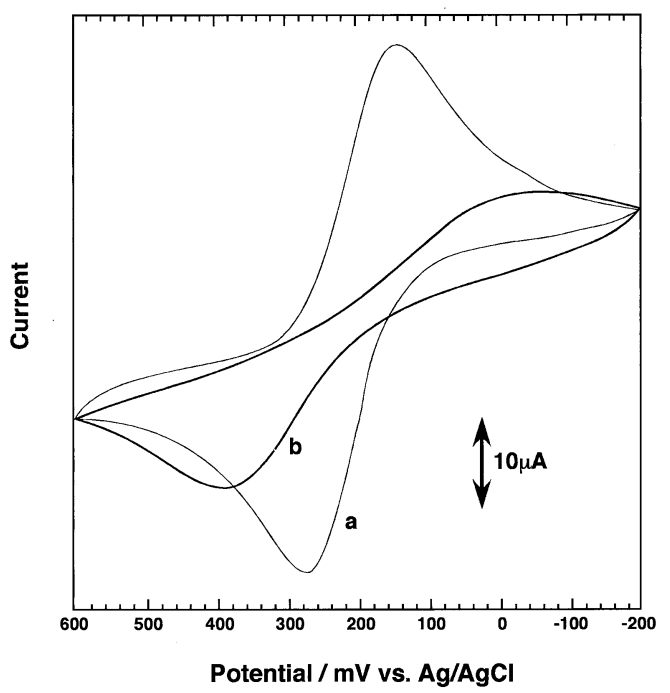

Fig. 1 Cyclic voltammograms of a protein-modified Au electrode (a) Bare gold disk electrode; (b) after a treatment of the electrode with the histidine-tagged hER-LBD. All measurements were performed in $10 \mathrm{mM}$ Tris buffer, $\mathrm{pH}=7.4,[\mathrm{KCl}]=100 \mathrm{mM}$, $\left[\mathrm{Fe}(\mathrm{CN})_{6}\right]^{4-13-}=5 \mathrm{mM}$, at $25^{\circ} \mathrm{C}$.

\section{5'-CGGGATCCGCTAGTGGGCGCATGTAGGC-3' (restriction sites underlined). The PCR-generated 0.78-kbp fragment was then digested with BamHI and NdeI and was subcloned into the pET16b vector (Novagen, USA). The correct insertion of the fragment was verified by DNA sequencing. \\ The resulting vector was allowed to express the hER-LBD in Escherichia coli BL21(DE3)pLysS cells (Novagen) using the $\mathrm{T} 7$ expression system. Overnight cultures were diluted with an LB medium ( $50 \mu \mathrm{g} / \mathrm{ml}$ ampicillin, $30 \mu \mathrm{g} / \mathrm{ml}$ chloramphenicol) to a volume of $500 \mathrm{ml}$ and grown at $37^{\circ} \mathrm{C}$ until an $\mathrm{OD}_{600}$ of 0.7 was reached. Protein expression was induced by the addition of isopropyl thiogalactopyranoside at a concentration of $1 \mathrm{mM}$. The tagged protein was purified with a Hitrap ${ }^{\mathrm{TM}}$ chelating column, essentially as described by the manufacture (Amersham Pharmacia Biotech, England) under native conditions. The target protein was practically homogeneous and did not contain any breakdown products.}

Synthesis of N,N-bis(carboxymethyl)-6-mercapto-hexylamine (1)

1 was synthesized as follows: 6-aminohexanol (4 mmol) and ethylbromoacetate $(17 \mathrm{mmol})$ were stirred under refluxing with diisopropyletylamine $(17 \mathrm{mmol})$ in acetonitrile for 2 days. The obtained $N, N$-bis(ethoxycarbonyl methyl)-6-aminohexanol was purified with preparative-layer chromatography on silica gel using ethylacetate-hexane 1:5 (v/v). This was heated with thionyl chloride under refluxing to chlorinate and then refluxed with thiourea in ethanol for 4 days. An excess amount of sodium hydroxide was added to the reaction mixture and refluxed for $2.5 \mathrm{~h}$. After cooling to room temperature, the $\mathrm{pH}$ of the solution was adjusted to 2 with hydrochloric acid. The reaction mixture was concentrated under reduced pressure. 1 was purified by a Sephadex LH-20 column with methanol-water 1:1 (v/v). The yield was $31 \%$.

\section{Electrode modification and cyclic voltammetry $(\mathrm{CV})$}

Histidine-tagged hER-LBD was immobilized onto an $\mathrm{Au}$ electrode via metal $\left(\mathrm{Ni}^{2+}\right)$ complexation. A 1-ethanol solution

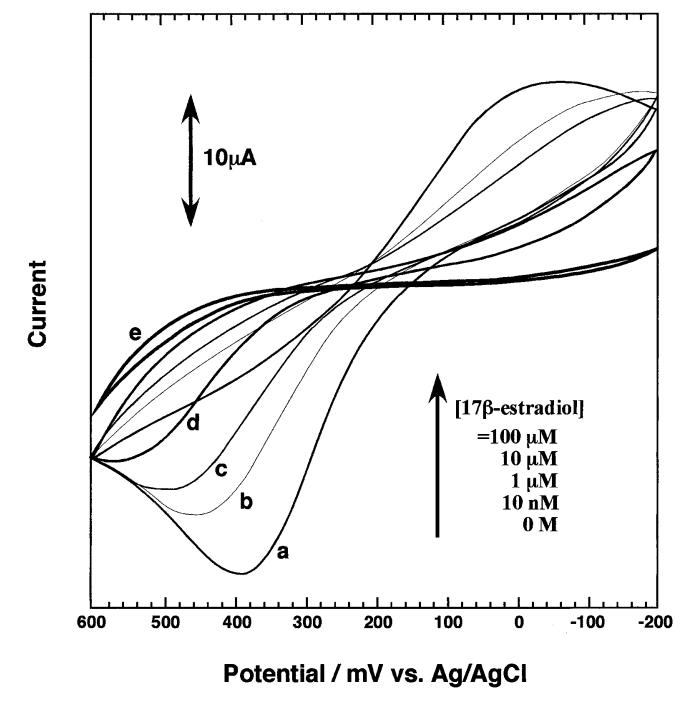

Fig. 2 Concentration dependence of estrogen to redox currents of ferrocyanide/ferricyanide redox couple on the protein-modified $\mathrm{Au}$ electrode. $17 \beta$-Estradiol concentrations $=$ (a) $0 \mathrm{M}$; (b) $10 \mathrm{nM}$; (c) 1 $\mu \mathrm{M}$; (d) $10 \mu \mathrm{M}$; and (e) $100 \mu \mathrm{M}$. All measurements were performed in $10 \mathrm{mM}$ Tris buffer, $\mathrm{pH}=7.4,[\mathrm{KCl}]=100 \mathrm{mM},\left[\mathrm{Fe}(\mathrm{CN})_{6}\right]^{4-13-}=5$ $\mathrm{mM}$, at $25^{\circ} \mathrm{C}$.

(11.3 mM) was dropped onto a polished Au disk electrode (1.6 $\mathrm{mm}$ diameter, Bioanalytical Systems, USA) and dried. The electrode was immersed into the $0.1 \mathrm{M} \mathrm{NiSO}_{4}$ aqueous solution for $5 \mathrm{~min}$, and then into the hER-LDB aqueous solution for 10 min at room temperature. Finally, the modified electrode was treated by a $10 \mathrm{mM}$ 6-mercaptohexanol aqueous solution at $4^{\circ} \mathrm{C}$ for $20 \mathrm{~min}$ to avoid a non-specific adsorption of estrogen.

Cyclic voltammetric and differential pulse voltammetric measurements were performed using a Bioanalytical Systems Co. (Model CV-50W) potentiostat. A platinum wire and a standard $\mathrm{Ag} / \mathrm{AgCl}$ (saturated $\mathrm{KCl}$ ) electrode were used as a counter and a reference electrode, respectively.

\section{Results and Discussion}

The hER is composed of six domains (domains A through F), some key functions have been assigned to each domain. ${ }^{11,12}$ The E domain, which is the ligand-binding domain responsible for selective binding of the cognate ligands with high affinity, is essential for efficient activation of transcription. In this study, we overexpressed the region of the hER using the Escherichia coli system. This expression system produced the truncated receptor as an in-frame fusion with ten consecutive histidine residues. This histidine-tag, located at the $\mathrm{N}$-terminus of the $\mathrm{hER}-\mathrm{LBD}$, is uncharged at physiological $\mathrm{pH}$, and generally does not affect the folding of the protein to which it is attached. The histidine-tagged hER-LBD can form a chelating complex with $\mathrm{Ni}(\mathrm{II})-1$. Thus, this complex was immobilized on an $\mathrm{Au}-$ electrode surface via $\mathrm{Ni}(\mathrm{II})-\mathbf{1}$, which should bind to Au with the sulfhydryl moiety by chemisorpion.

The immobilization of the recombinant protein was examined using cyclic voltammetry at $25 \mathrm{mV} \mathrm{s}^{-1}$ in a sample buffer [10 $\mathrm{mM}$ Tris- $\mathrm{HCl}$ ( $\mathrm{pH} \mathrm{7.4),} 100 \mathrm{mM} \mathrm{KCl}$ ] containing $5 \mathrm{mM}$ each of $\mathrm{K}_{4} \mathrm{Fe}(\mathrm{CN})_{6}$ and $\mathrm{K}_{3} \mathrm{Fe}(\mathrm{CN})_{6}$. The peak currents due to the reversible redox reaction of the marker ions decreased on the protein-modified electrode, as compared with that of a bare one 


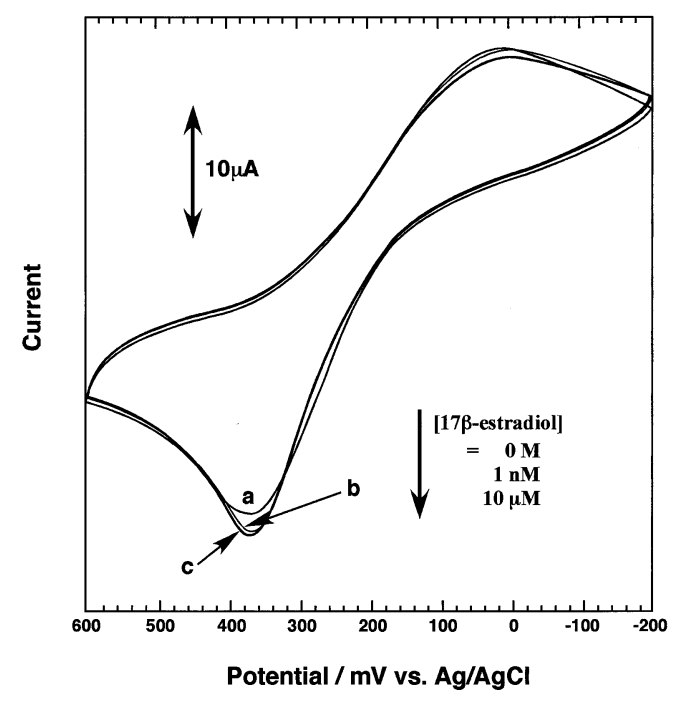

Fig. 3 Cyclic voltammograms of an Au electrode modified with 1 alone in the absence and presence of $17 \beta$-estradiol. 17 $\beta$-Estradiol concentrations $=$ (a) $0 \mathrm{M}$; (b) $1 \mathrm{nM}$; and (c) $10 \mu \mathrm{M}$. All measurements were performed after a treatment with 6mercaptohexanol in $10 \mathrm{mM}$ Tris buffer, $\mathrm{pH}=7.4,[\mathrm{KCl}]=100 \mathrm{mM}$, $\left[\mathrm{Fe}(\mathrm{CN})_{6}\right]^{4-13-}=5 \mathrm{mM}$, at $25^{\circ} \mathrm{C}$

(Fig. 1). This phenomenon was attributed to immobilized hERLBD, which perturbed the electrical contact and electrontransfer rate between the redox probe and the electrode surface.

The protein modified Au-electrode was applied to the electrochemical detection of estrogen on an electrode surface. Figure 2 shows cyclic voltammograms of the electrode in the absence and presence of $17 \beta$-estradiol. The redox current was suppressed by $17 \beta$-estradiol in a concentration-dependent manner. The electrode modified with 1 alone did not respond to $17 \beta$-estradiol after a treatment with 6-mercaptohexanol, which is a blocking agent ${ }^{8}$ to exclude nonspecific adsorption of estrogen (Fig. 3). Thus, the results demonstrate that the current depression was certainly caused by complex formation between ER and $17 \beta$-estradiol on the electrode surface.

However, it is not clear how the complexation influences amperometric transduction of the redox marker at the electrode surface. The most plausible possibility is a conformational change of the hER-LBD on the electrode surface. The transcriptional activation by steroid hormone receptors including hER is attributed to conformational changes induced by a specific binding of their ligands, followed by homodimerization to bind to response elements on the genome. $^{13,14}$ A functional analysis of mutant receptors has indicated that the major dimerization interface is located in the ligand-binding domain of the hER. ${ }^{3}$ Interestingly, Witkowska et al. observed positive charges of hER ligand-binding domain were decreased dramatically with ligand-binding under physiological conditions. ${ }^{15}$ It has not been clarified whether the immobilized hER-LBD on the Au-electrode formed a similar homodimer in the presence of $17 \beta$-estradiol. However, it was likely that an electrochemical reaction of a negatively charged redox ion was suppressed by an alteration in the electrostatic property of the protein layer on the electrode surface (Fig. 4).

In conclusion, the detection system that we have described here showed a good response to estrogen, which has long been known to play critical roles in the development of feminine

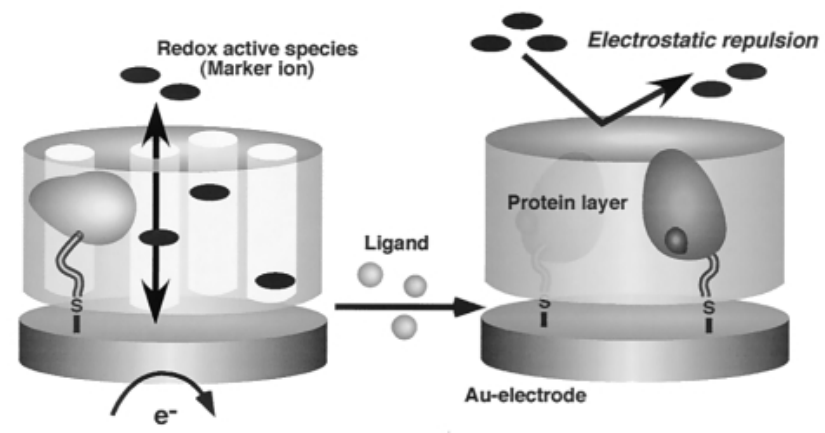

Fig. 4 Schematic illustration of an electrochemical estrogen sensing system based on the ligand-receptor interaction.

secondary sexual characteristic. Given the need to test a very large number of chemicals for the endocrine-disrupting potential, short-term in vivo and in vitro tests that are rapid, reliable, and inexpensive must be development to screen chemicals. ${ }^{16}$ Our results reveal a new concept for the development of a high-throughput screening method, without using a radioactive substrate, to identify new ligands for hER.

\section{Acknowledgements}

We thank Drs. Thomas C. Spelsberg and Steaven A. Harris (Mayo Clinic, Rochester, MN USA) for kindly providing plasmid pHEGO-Hyg, and Dr. Koji Nakano (Kyushu University) for helpful discussion about electrochemistry. This work has been funded by grants from the Steel Industry Foundation for the Advancement of Environmental Protection Technology, and Showa Shell Sekiyu Foundation Promotion of Environmental Research to M. Murata.

\section{References}

1. R. Bolger, T. E. Wiese, K. Ervin, S. Nestich, and W. Checovich, Environ. Health Perspectives, 1998, 106, 551.

2. J. Nishikawa, K. Saito, F. Dakeyama, M. Matsuo, and T. Mishikawa, Toxicol. Appl. Pharmacol., 1999, 154, 76.

3. M. G. Parker, Vitamins and Hormones, 1995, 51, 267.

4. A. E. G. Cass (ed.), "Biosensores. A Practical Approach", 1990, IRL Press, New York.

5. I. Willner and E. Katz, Angew. Chem. Int. Ed., 2000, 39 , 1180 .

6. T. Ihara, M. Nakayama, M. Murata, K. Nakano, and M. Maeda, Chem. Commun., 1997, 1609.

7. M. Maeda, K. Nakano, and M. Takagi, in "Diagnostic Biosensor Polymers", ed. A. M. Usami and N. Akmal, 1994, American Chemical Society, Washington D.C., 238.

8. Y. Katayama, M. Nakayama, H. Irie, K. Nakano, and M. Maeda, Chem. Lett., 1998, 1181.

9. Y. Katayama, Y. Ouchi, M. Nakayama, M. Maeda, H. Higashi, and Y. Kudo, Chem. Lett., 1997, 883.

10. M. Sugawara, K. Kojima, H. Sazawa, and Y. Umezawa, Anal. Chem., 1987, 59, 2842.

11. R. White, J. A. Lee, M. Needham, J. Ham, and M. Parker, Mol. Endocrinol., 1987, 1, 735 .

12. V. Kumar, S. Green, G. Stack, M. Berry, J-R. Jin, and P. Chambon, Cell, 1987, 51, 941.

13. V. Kumar and P. Chambon, Cell, 1988, 55, 145. 
14. S. E. Fawell, J. A. Lees, R. White, and M. G. Parker, Cell, 1990, 60, 953.

15. H. E. Witkowska, B. N. Green, M. Carlquist, and C. H. L. Shackleton, Steroids, 1996, 61, 433.

16. R. J. Kavlock, G. P. Daston, C. DeRosa, P. Fenner-Crisp,
L. E. Gray, S. Kaattari, G. Lucier, M. J. Mac, C. Maczka, R. Miller, J. Moore, R. Rolland, G. Scott, D. M. Sheehan, T. Sinks, and H. A. Tilson, Environ. Health Perspectives, 1996, 104 Suppl. 4, 1. 